\title{
Where is the best site for embryo transfer? A study of relation of embryo-fundal distance with pregnancy rate in ICSI-ET cycle
}

\author{
Shreedevi J. Tanksale ${ }^{1}$, Purnima K. Nadkarni ${ }^{2}$, Aditi A. Nadkarni ${ }^{3}$, Prabhakar Singh ${ }^{4}$ \\ ${ }^{1}$ Fellow, Nadkarni Hospital and Test tube Baby Centre, $21{ }^{\text {st }}$ Century Fertility Centers, Gujarat, India \\ ${ }^{2}$ Consultant Fertility Specialist, Nadkarni Hospital and Test tube Baby Centre, $21^{\text {st }}$ Century Fertility Centers, Gujarat, \\ India \\ ${ }^{3}$ Consultant Fertility Specialist, Nadkarni Hospital and Test tube Baby Centre, $21{ }^{\text {st }}$ Century Fertility Centers, Gujarat, \\ India \\ ${ }^{4}$ Chief Embryologist, Nadkarni Hospital and Test tube Baby Centre, $21{ }^{\text {st }}$ Century Fertility Centers, Gujarat, India
}

Received: 05 June 2016

Accepted: 01 July 2016

\section{*Correspondence:}

Dr. Shreedevi J. Tanksale,

E-mail: shreedevitanksale@ hotmail.com

Copyright: $\odot$ the author(s), publisher and licensee Medip Academy. This is an open-access article distributed under the terms of the Creative Commons Attribution Non-Commercial License, which permits unrestricted non-commercial use, distribution, and reproduction in any medium, provided the original work is properly cited.

\section{ABSTRACT}

Background: Embryo transfer is the ultimate and most critical step of IVF-ICSI treatment cycle. It has a significant impact on the success rate of IVF cycle. Undoubtedly, it has significant impact of the pregnancy rate and implantation rate. Along with the other factors the impact of the site of embryo transfer has also been studied by several investigators. There is lack of clear consensus about the ideal site of embryo transfer.

Methods: This study includes a retrospective analysis of 200 embryo transfers done in 200 infertile couples done at our infertility clinics from January 2016 to March 2016. Transfer cycles of gamete donation, embryo donation and frozen embryos were excluded from the study. The study involved patients undergoing their first IVF- ICSI cycle with fresh embryo transfer at our IVF Unit. All patients were stimulated using Antagonist protocol starting Gonadotropins from day $2 / 3$ of menses.

Results: The clinical pregnancy rate was highest $(55.2 \%)$ in group 2 when the embryo fundal distance was more than $10 \mathrm{~mm}$ but less than or equal to $15 \mathrm{~mm}$. In group 3 when embryos were placed beyond $15 \mathrm{~mm}$ distance from the fundus, the clinical pregnancy rate was $34.66 \%$. The lowest pregnancy rate - 30\% was found in group 1 when embryos were places less than $10 \mathrm{~mm}$ from fundus. There was only a single case of ectopic pregnancy in the study group. The ectopic pregnancy was seen in group 1 . There two cases of abortion each in group 2 . The miscarriage rate was higher in group $3-5.33 \%$ as compared to $1.9 \%$ in group 2 . The sample size was small to determine if these results were significant enough.

Conclusions: The present study demonstrates that higher pregnancy rates are obtained if the embryos are selectively placed at a distance between $10 \mathrm{~mm}$ to $15 \mathrm{~mm}$ from the fundal endometrial surface. It is not possible to determine exact location of embryo placed in utero by any method. The findings of our study can be considered as a guiding force by clinicians.

Keywords: Embryo transfer, ICSI, IVF-ET, Pregnancy rate 


\section{INTRODUCTION}

Embryo transfer is the most important and critical step in the IVF-ICSI treatment. The technique used to perform embryo transfer (ET) is considered one of the most relevant factors affecting the final outcome of human in vitro fertilization (IVF). ${ }^{1}$ The type of catheter, the operator's skill, the amount of loaded medium, the presence of mucus or blood in or around the catheter, any difficulty in entering the uterine cavity have all been recognized as variables affecting the IVF success rate., Along with these factors the impact of the site of embryo transfer has also been debated by several investigators. However there is lack of clear consensus about the optimal site of embryo transfer. There has been debate regarding which area within the endometrial cavity is ideal for embryo placement in order to obtain the highest pregnancy rate. The optimal distance from the site of embryo transfer to the fundal area (embryo-fundal distance, EFD) has not yet been identified. In clinical touch embryo transfer, the distance at which embryo is transferred is variable depending on the uterine cavity length. In ultrasound guided embryo transfer, the embryos can be delivered at a specified distance from fundal endometrial surface, as per the operator.

Several studies demonstrated a significant effect of embryo transfer depth on IVF and embryo transfer outcomes. ${ }^{4-7}$ The common end-result achieved by these studies was that embryo transfer at or within $10 \mathrm{~mm}$ of the fundal endometrial surface was associated with a lower pregnancy rate (PR) compared with embryo transfer $>10 \mathrm{~mm}$ below the fundal endometrial surface. ${ }^{5-7}$ In the present study, we measured by trans-vaginal ultrasound the distance from the air bubble injected with the embryos and the fundal endometrial surface (EFD) in order to assess if EFD affects pregnancy and implantation rates.

\section{METHODS}

This study includes a retrospective analysis of 200 embryo transfers done in 200 infertile couples done at our infertility clinics from January 2016 to March 2016. Transfer cycles of gamete donation, embryo donation and frozen embryos were excluded from the study. The study involved patients undergoing their first IVF- ICSI cycle with fresh embryo transfer at our IVF Unit. All patients were stimulated using antagonist protocol starting Gonadotropins from day $2 / 3$ of menses. The gonadotropin dose was modified according to the patients' ovarian reserve and ovarian response as determined by trans-vaginal ultrasound assessment of follicular development. When at least three follicles reached a diameter of $17 \mathrm{~mm}$, recombinant hCG (250 $\mathrm{mcg}$ ) was administered as ovulation trigger. Oocyte retrieval was carried out under general anesthesia using trans-vaginal ultrasound-guided puncture 36 hours after the injection of hCG.
Oocytes were inseminated 4-6 hours after retrieval by ICSI using fresh ejaculates and cultured for 3 days. Embryo quality was assessed according to the number and form of blastomeres and the percentage of cytoplasmic fragmentation. All patients were transferred with two embryos on day 5 post insemination. All transfers were performed in the same operating room by the same gynecologist-embryologist pair. All patients underwent the embryo transfer procedure as the standard protocol of the IVF unit. The patients were placed in the lithotomy position. The perineum and vagina was gently cleaned using normal saline and the cervix was exposed using two sims specula (one above and one below). The cervical mucus was flushed away with a syringe containing washing media and removed with absorbent gauze. With a filled bladder, all embryo transfers were carried out under ultrasound guidance. The soft sydney embryo transfer catheter was used for all embryo transfers the catheter was introduced into the endometrial cavity through the cervix up to the point estimated for transfer. The distance between the end of the fundal endometrial surface and the catheter tip was then measured by ultrasound and noted.

In all transfers the medium containing the embryos was gently expelled into the uterine cavity under sonographic control, which allowed the visualization of air bubbles between the embryos (transfer bubbles). The catheter was immediately, gently removed and examined under a stereomicroscope to be sure that all embryos had been transferred. After the procedure, patients remained in bed for 20 minutes.

Starting from one day after oocyte pick-up, all patients received luteal phase support with vaginal micronized progesterone. Pregnancy was diagnosed by an increasing serum concentration of b-hCG 14 days after oocyte pickup and a serum b-hCG level $>40 \mathrm{mIU} / \mathrm{mL}$ was considered a positive pregnancy test. The cases with $b$-hCG levels $<40 \mathrm{mIU} / \mathrm{mL}$ were considered negative for pregnancy during analysis. These patients underwent beta-hCG follow- up every 4 days. Those with decreasing levels were considered to have biochemical pregnancies. Those with increasing levels were closely followed-up as these patients risked an ectopic pregnancy.

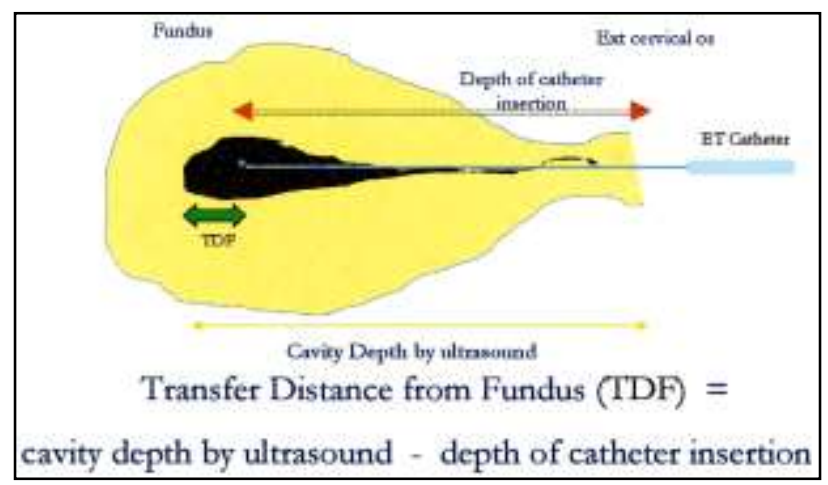

Figure 1: Embryo fundal distance. 
Statistical analysis was performed using the SPSS (statistical program for social sciences, Chicago, IL) program. Data were characterized by means, SD, and percentages.

\section{RESULTS}

According to depth of embryo transfer, the patients in this study were divided into 3 groups. In 20 cases (10\%), embryos were transferred at or within $10 \mathrm{~mm}$ of the fundal endometrial surface (group 1). In 105 cases $(52.5 \%)$, embryos were transferred at a distance $>10 \mathrm{~mm}$ but < or equal to $15 \mathrm{~mm}$ from the fundal endometrial surface (group 2). In 75 cases (37.5\%), embryos were transferred at a distance $>15 \mathrm{~mm}$ but $<20 \mathrm{~mm}$ from the fundal endometrial surface (group 3 ).

Table 1: General characteristics of patients in the three groups studied.

\begin{tabular}{|llll|}
\hline Age $($ years $) \pm$ SD & $33.4 \pm 5.2$ & $34.7 \pm 4.8$ & $35.1 \pm 4.1$ \\
\hline BMI $\left(\mathrm{kg} / \mathrm{m}^{2}\right) \pm$ SD & $22.6 \pm 1.8$ & $23 \pm 2$ & $22.9 \pm 1.6$ \\
\hline $\begin{array}{l}\text { Duration of infertility } \\
\text { (years) } \pm \text { SD }\end{array}$ & $6.7 \pm 2.8$ & $6.3 \pm 2.4$ & $7.1 \pm 2,5$ \\
\hline $\begin{array}{l}\text { Basal FSH (day2-4) } \\
\pm \text { SD }\end{array}$ & $8 \pm 2.8$ & $6.9 \pm 2.3$ & $7.6 \pm 3.2$ \\
\hline $\begin{array}{l}\text { Antral follicle } \\
\text { count }+ \text { SD }\end{array}$ & $11 \pm 5$ & $12 \pm 6$ & $11 \pm 4$ \\
\hline
\end{tabular}

Basal FSH levels were similar in all three groups. Also, the basal antral follicle counts were similar in all groups.

Table 2: Distribution of cause of infertility in the study group.

\begin{tabular}{|llll|}
\hline Cause of infertility & Group 1 & Group 2 & Group 3 \\
\hline Male factor & 10 & 47 & 32 \\
\hline Tubal factor & 8 & 21 & 18 \\
\hline Unexplained & 3 & 28 & 13 \\
\hline Endometriosis & 2 & 3 & 7 \\
\hline Low ovarian reserve & 3 & 8 & 10 \\
\hline
\end{tabular}

Some patients had multiple factors contributing as a cause of infertility. The most common factors leading to infertility included male factor and tubal factor.

Table 3: Ovarian stimulation characteristics, oocyte retrieval.

\begin{tabular}{|llll|}
\hline Variable & Group 1 & Group 2 & Group 3 \\
\hline $\begin{array}{l}\text { Endometrial } \\
\text { thickness }(\mathrm{mm}) \pm \mathrm{sd}\end{array}$ & $11 \pm 2.3$ & $12.0 \pm 5.2$ & $12.1 \pm 5.8$ \\
\hline Oocytes retrieved $\underline{\mathrm{sd}}$ & $12 \pm 4$ & $14 \pm 6$ & $12 \pm 5$ \\
\hline M2 oocytes $\underline{\mathrm{sd}}$ & $8 \underline{ \pm} 3$ & $11 \pm 3$ & $9 \pm 3$ \\
\hline
\end{tabular}

Among the three groups, group 2 and 3 had similar endometrial thickness on day on HCG trigger. There was no much difference in the number of oocytes retrieved and metaphase 2 oocytes.

Table 4: Pregnancy rates and outcome of gestation.

\begin{tabular}{|llll|}
\hline Variable & $\begin{array}{l}\text { Group 1 } \\
\mathbf{N}=20 \\
(10 \%)\end{array}$ & $\begin{array}{l}\text { Group 2 } \\
\mathbf{N}=105 \\
(52.5 \%)\end{array}$ & $\begin{array}{l}\text { Group } 3 \\
\mathbf{N}=75 \\
(37.5 \%)\end{array}$ \\
\hline $\begin{array}{l}\text { Clinical } \\
\text { pregnancy/em } \\
\text { bryo transfer } \\
(\%, \mathrm{n})\end{array}$ & $\begin{array}{l}30 \% \\
(6 / 20)\end{array}$ & $\begin{array}{l}55.2 \% \\
(58 / 105)\end{array}$ & $\begin{array}{l}34.66 \% \\
(26 / 75)\end{array}$ \\
\hline $\begin{array}{l}\text { Implantation } \\
\text { rate }(\%, \mathrm{n})\end{array}$ & $20 \%$ & $35 \%$ & $25.33 \%$ \\
\hline $\begin{array}{l}\text { Miscarriage } \\
\text { rate }(\%, \mathrm{n})\end{array}$ & - & $\begin{array}{l}(75 / 40) \\
(2 / 105)\end{array}$ & $\begin{array}{l}(38 / 150) \\
(4 / 75)\end{array}$ \\
\hline Ectopic rate & $5 \%$ & - & - \\
\hline
\end{tabular}

The clinical pregnancy rate was highest $(55.2 \%)$ in group 2 when the embryo fundal distance was more than $10 \mathrm{~mm}$ but less than or equal to $15 \mathrm{~mm}$. In group 3 when embryos were placed beyond $15 \mathrm{~mm}$ distance from the fundus, the clinical pregnancy rate was $34.66 \%$. The lowest pregnancy rate - 30\% was found in group 1 when embryos were places less than $10 \mathrm{~mm}$ from fundus. There was only a single case of ectopic pregnancy in the study group. The ectopic pregnancy was seen in group 1. There two cases of abortion each in group 2. The miscarriage rate was higher in group $3-5.33 \%$ as compared to $1.9 \%$ in group 2. The sample size was small to determine if these results were significant enough.

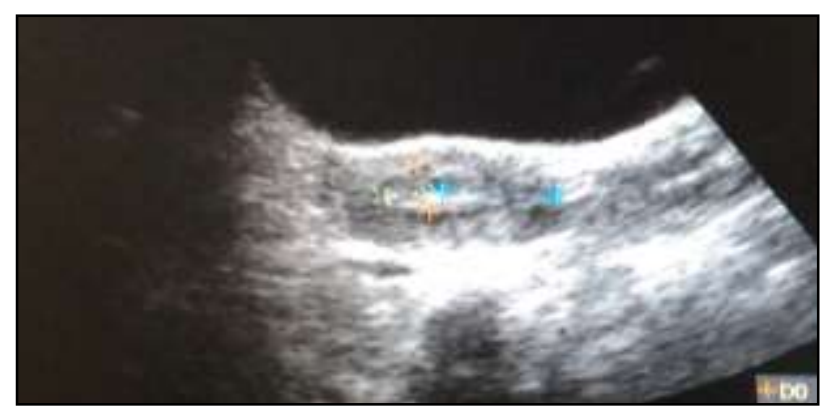

Figure 2: Measurement of endometrial cavity prior to embryo transfer.

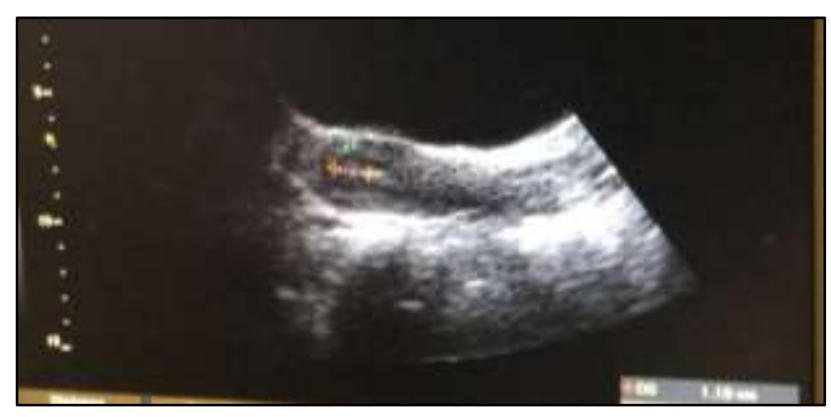

Figure 3: Measurement of embryo fundal distance after embryo transfer. 


\section{DISCUSSION}

The success of an ART cycle depends on multiple factors. In spite of high fertilization and cleavage rates, failure of implantation serves as a major step in the success of ART. Though the step of embryo transfer may be considered by few as an easy step, it is a crucial and rate limiting step. Numerous studies have been conducted on improving ovarian stimulation, oocyte insemination and culture procedures and their effect on success of ICSI cycle. Until recently, the importance of influence of depth of embryo transfer on the outcome of IVF cycle was not given much importance.

Strickler et al was the first to describe in 1985 the use of ultrasound to guide an embryo transfer. ${ }^{8}$ Since then, trans-vaginal and mainly abdominal ultrasound have been gradually added to achieve an a traumatic, controlled, quick an anatomically defined embryo transfer., Accurate knowledge of the uterine depth and cervical trajectory has always been regarded as a mandatory requirement to achieve high pregnancy rates. ${ }^{10}$

Some of the initial studies on influence of embryo transfer depth on implantation rates after IVF were conducted by Pope et al and Coroleu B et al. The study by $\mathrm{B}$ Coroleu et al suggested that the depth of embryo placement in the uterine cavity is amongst the important factors to be considered in success of IVF cycle. ${ }^{5}$ In their prospective randomized study, Coroleu et al randomized 180 consecutive patients undergoing ultrasound- guided embryo transfer into three study groups according to the distance between the tip of the catheter and the uterine fundus at the moment of the embryo deposition in the lumen of the endometrial cavity. ${ }^{5}$ First group consisted of embryo transfer at $10 \pm 1.5 \mathrm{~mm}$, second group at $15 \pm 1.5$ $\mathrm{mm}$, and third group, at $20 \pm 1.5 \mathrm{~mm}$. This study proved that a higher implantation rate was obtained in groups 2 and 3 compared with group 1 .

A study by Pope et al suggested that after controlling for age, number of good grade embryos, use of donor eggs, stimulation protocol, procedure type (fresh, frozen, ICSI), transfer physician, assisted hatching, and number of previous cycles, the results from a multiple logistic regression model demonstrated a significant association between embryo transfer depth and clinical PR (OR 1.11; 95\% CI 1.07-1.14; $\mathrm{P}<.001$ ). This suggests that for every additional millimeter the embryos are deposited away from the fundus, the odds of clinical pregnancy increase by $11 \%{ }^{6}$

The possible factors affecting implantation rates before, during, and after embryo transfer have been widely researched. Among these factors are ultrasound guidance, transfer catheter type, catheter-loading technique, uterine cavity fluid, blood or mucus effects, retained embryos, mock transfer, myometrial contractions, and facility of the procedure.
In their study, Frankfurter et al analyzed their videotapes of embryo transfers in pregnant and non-pregnant cycles. ${ }^{4}$ They concluded that improved embryo transfer results were obtained when the embryos were placed at lower levels in the uterine cavity.

Pacchiarotti et al performed 104 consecutive embryo transfers. ${ }^{7}$ The patients were matched in two groups according to the distance between the tip of the catheter and the uterine fundus at transfer (group A $>10$ and $<15$ $\mathrm{mm}$; group B $<10 \mathrm{~mm}$ ). Clinical PRs varied significantly between the two groups and it was $27.7 \%$ in group $\mathrm{A}$ and $14 \%$ in group $\mathrm{B}(\mathrm{P}<.05)$.

After these initial studies, there was need for a large randomized prospective study. Tiras et al conducted a study including retrospective analysis of 5,055 ultrasound- guided embryo transfers belonging to 3,930 infertile couples performed in a single center. ${ }^{11}$ According to the depth of embryo transfer, patients in this study have been classified into five groups. In 31 cases $(0.6 \%)$, embryos were transferred at or within $10 \mathrm{~mm}$ of the fundal endometrial surface (group 1). In 676 cases $(13.4 \%)$, embryos were transferred at a distance $>10 \mathrm{~mm}$ but $<15 \mathrm{~mm}$ from the fundal endometrial surface (group 2). In 2,690 cases (53.2\%), embryos were transferred at a distance $>15 \mathrm{~mm}$ but $<20 \mathrm{~mm}$ from the fundal endometrial surface (group 3). In 1,296 cases (25.6\%), embryos were transferred at a distance $>20 \mathrm{~mm}$ but $<25$ $\mathrm{mm}$ from the fundal endometrial surface (group 4). And finally, in 362 cases (7.2\%), embryos were transferred at a distance $>25 \mathrm{~mm}$ from the fundal endometrial surface. The study demonstrated that optimum PRs and ongoing PRs are obtained if the embryos are selectively replaced at a distance $>10 \mathrm{~mm}$ from the fundal endometrial surface. In addition, results showed that unintentional replacement of embryos within $1 \mathrm{~cm}$ of the uterine fundus may not have an impact on the PRs. However, beyond $1 \mathrm{~cm}$ of the fundus, deposition of embryos in any place within the cavity does not have a negative effect on the PRs. They also found that abortion rate was similar across all groups. Although the site of embryo replacement may have an influence on PRs, the miscarriage rate is not affected by the site of embryo transfer once pregnancy is established.

In our study, number of embryo transfers at a distance $<10 \mathrm{~mm}$ from the fundal endometrial surface (group 1) was very small compared with the embryo transfers at other distances. The pregnancy rates in our study group are higher in embryo transfers done in group 2 and 3 . The highest pregnancy rate was seen in group 2- when embryos were placed between $10 \mathrm{~mm}$ to $15 \mathrm{~mm}$ distance from the uterine fundus. These results are similar to the studies mentioned above. In our study group, the baseline characteristics of study population were similar. The ovulation protocol and trigger were uniform. There was no difference in the number of oocytes retrieved. The consultant reproductive endocrinologist and embryologist were same in all the patients. The number of embryos 
transferred and procedure of embryo transfer were uniform throughout the study group.

The spontaneous abortion rates observed in the present study was slightly higher in group 3 . However larger studies have suggested that the miscarriage rate is not affected by the site of embryo transfer once pregnancy is established.

\section{CONCLUSION}

In conclusion, the present study demonstrates that higher pregnancy rates are obtained if the embryos are selectively placed at a distance between $10 \mathrm{~mm}$ to $15 \mathrm{~mm}$ from the fundal endometrial surface. However, beyond 1 $\mathrm{cm}$ of the fundus, deposition of embryos in any place within the cavity does not have a negative effect on the pregnancy rates. These observations can be useful for ART clinics that are facing implantation problems in spite of good embryo quality. There has been no fixed guideline for the exact position at which embryos should be placed. It is not possible to determine exact location of embryo placed in utero by any method. The findings of our study can be considered as a guiding force by clinicians.

\section{Funding: No funding sources}

Conflict of interest: None declared

Ethical approval: The study was approved by the Institutional Ethics Committee

\section{REFERENCES}

1. Mains L, Van Voorhis BJ. Optimizing the technique of embryo transfer. Fertil Steril. 2010;94:785-90.

2. Ghazzawi IM, Al-Hasani S, Karaki R, Souso S. Transfer technique and catheter choice influence the incidence of trans-cervical embryo expulsion and the outcome of IVF. Hum Reprod. 1999;14:677-682.

3. Schoolcraft WB, Surrey ES, Gardner DK. Embryo transfer: techniques and variables affecting success. Fertil Steril. 2001;76:863-70.

4. Frankfurter D, Silva CP, Mota F, Trimarchi JB, Keefe D. The transfer point is a novel measure of embryo placement. Fertil Steril. 2003;79:1416-21.

5. Coroleu B, Barri PN, Carreras O, Martinez F, Parriego M, Hereter L, et al. The influence of the depth of embryo replacement into the uterine cavity on im plantation rates after IVF: a controlled, ultrasoundguided study. Hum Reprod. 2002;17:3416.

6. Pope CS, Cook EKD, Arny M, Novak A, Grow DR. Influence of embryo transfer depth on in vitro fertilization and embryo transfer outcomes. Fertil steril. 2004;81:51-8.

7. Pacchiarotti A, Mohamed MA, Micara G, Tranquilli D, Linari A, Espinola SMB, et al. The impact of the depth of embryo replacement on IVF outcome. J Assist Reprod Genet. 2007;24:189-93.

8. Strickler RC, Christianson C, Crane JP, Curato A, Knight AB, Yang V. Utrasound guidance for human embryo transfer. Fertil Steril. 198;43:54-61.

9. Sallam HN, Sadek SS. Ultrasound guided embryo transfer: a meta-analysis of randomized controlled trials. Fertil Steril. 2003;80:1042-6.

10. Matorras R, Urquijo E, Mendoza R, Corcostequi B, Exposito A, Rodrguez-Escudero FJ. Ultrasound guided embryo transfer improves pregnancy rates and increases frequency of easy transfers. Hum Reprod. 2002;17:1762-6.

11. Tiras B, Polat M, Korucuoglu U, Zeyneloglu B, Yarali H. The impact replacement depth on in-vitro fertilization and embryo transfer outcomes. Fertil and Steril. 2010;94:1341-5.

Cite this article as: Tanksale SJ, Nadkarni PK, Nadkarni AA, Singh P. Where is the best site for embryo transfer? A study of relation of embryofundal distance with pregnancy rate in ICSI-ET cycle. Int J Reprod Contracept Obstet Gynecol 2016;5:2661-5. 